\title{
Integrating Environmental Requirements into Quality Function Deployment for Designing Eco-Friendly Product
}

\author{
Pregiwati Pusporini, Kazem Abhary, and Lee Luong
}

\begin{abstract}
Nowadays, the green manufacturing that relates to the environmental issues is growing and spreading into many aspects of industry. This issue is pushing every industry to increase their awareness of the environmental issues by developing and creating environmentally friendly products. The acceptance of products is based on quality as well as environmental performance. This means that to be competitive in the global market, the quality of products should meet the customer needs and also the environmental requirements. This paper proposes the integration of environmental requirements into Quality function deployment (QFD) methodology for designing and creating eco-friendly products. In this paper fuzzy logic is employed in conjunction with house of quality (HOQ) for integration into QFD to achieve this aim.
\end{abstract}

Index Terms-Environmentally friendly product, quality function deployment, fuzzy logic, house of quality.

\section{INTRODUCTION}

Environmentally friendly products are becoming a most important issue for the manufacturing industry which would force the industry to increase their awareness of the environmental consideration and produce products that would meet the customer and environmental requirements. Product would be accepted based on not only the quality but also meeting the environmental requirements. Pusporini, Abhary and Luong [1] highlighted the introducing environmental aspects into continuous improvement methodology such as lean six sigma for sustainable product development. As a result, it is important to put environmental requirements into product design and process development. Karlsson and Luttropp [2] pointed out that the main concern for eco-design is integration of environmental consideration into product development process that would imply how to create smart products or methods, effective system solutions and attractive designs.

Quality function deployment (QFD) that is well-known as a powerful method in the product design and development has been employed successfully in many manufacturing industries. This approach is driven from the customer needs that would be transformed into high characteristics of

Manuscript received November 4, 2012; revised January 10, 2013.

Pregiwati Pusporini is with the School of Advanced Manufacturing and Mechanical Engineering, University of South Australia, Australia and Lecturer at Department of Industrial Engineering, University of Muhammadiyah Gresik, East Java, Indonesia (e-mail: puspy001@mymail.unisa.edu.au).

Kazem Abhary is with the Sustainable Mech. And Manufacturing Design at School of Advanced Manufacturing and Mechanical Engineering, University of South Australia, Australia (e-mail: Kazem.Abhary@unisa.edu.au).

Lee Luong is with the Manufacturing Engineering at School of Advanced Manufacturing and Mechanical Engineering, University of South Australia, Australia (e-mail: Lee.Luong@unisa.edu.au). products. Karsak [3] highlighted that the QFD is a customer-oriented design tool for integrating many cross functional aspects of organisation like marketing, design engineering and manufacturing in order to develop and improve quality products to enhance customer satisfaction. Further extendion of QFD is needed to address environmental considerations during product design and development for further customer satisfaction. Cristofari, Deshmukh and Wang [4] proposed the green QFD (GQFD) as a new methodology in order to incorporate environmental analysis at the product design stage. The authors mentioned that the Green QFD would consider quality requirements, environmental impacts and also production cost during the design stage. Zhang et al [5] developed Green quality function deployment-II (GQFD-II) for product development and improvement. The authors used the integration between life cycle assessment (LCA) and life cycle costing (LCC) into QFD and deployed matrices of the QFD into quality, environmental and cost requirements. Masui et al [6] highlighted the environmental voice of customer (VOC) and environmental engineering metric (EM) for QFD to develop QFD for environment (QFDE). Sakao [7] proposed a QFD-centered design methodology that involves the integration of three main tools namely, life cycle assessment (LCA), quality function deployment for environment (QFDE) and theory of inventive problem solving (TRIZ) with the aim to support the design of environmentally friendly products. Cagno and Trucco [8] proposed a different approach from QFD methodology. The authors used matrix approach as a simplified life cycle assessment that would enhance QFD to create integrated green and quality function deployment. Kuo, Wu and Shieh [9] developed Eco-quality function deployment (Eco-QFD) in order to include the environmental consideration into QFD as a quality system tool to enhance customer satisfaction. Bowea and Wang [10] highlighted the integration between LCA technique into house of quality (HOQ) in QFD to analyse and evaluate the significant environmental impacts for the purpose of environmental improvement. Pusporini, Abhary and Luong [11] proposed environmental performance as key performance indicators in the lean six sigma methodology to achieve overall competitiveness of product. This paper proposes the integration of environmental requirements into QFD to identify the most significant environmental indicators for design and manufacture of environmentally friendly products.

\section{BRIEF LITERATURE REVIEW: QUALITY FUNCTION DEPLOYMENT}

The concept of quality function deployment (QFD) is developed to consider the quality at early stage of the design 
process. Tan, Xie and Chia [12] mentioned that QFD is for clearly understanding and applying both engineering and management. Rahim and Baksh [13] mentioned that the application of QFD method has been conducted successfully in both improving quality of existing products and developing new products. Kumar, Antony and Dhakar [14] highlighted that QFD is a powerful approach to achieve the customer satisfaction by responding to the customer needs and doing benchmark to optimize the process, to improve the output value and also to minimize the use of resources. Celik et al [15] pointed out that this approach is a systematic concept to establish and translate the customer needs into product development including product planning, engineering and manufacturing. Kannan [16] mentioned that QFD is a powerful approach for product design and development by planning and realizing the quality of products that would meet the customer expectations.

The application of the QFD has been conducted widely for the competitive product or service quality. Customer needs commonly relate to the performance of the product or service such as quality, cost, the availability, durability and time delivery. Basically, the qualitative research should be conducted properly in order to identify the customer needs. For which several tools like questionnaire, discussion, brainstorming and historical data can be adopted. The main concern of the QFD approach is how to construct the house of quality (HOQ) including how to identify the correlation between the voice of customers or customer needs (commonly called Whats) and the engineering characteristics (commonly called Hows). The development of HOQ would involve cross-functional team or members from many different departments in industry. Karsak [17] highlighted that transferring value is the main purpose of the QFD that would be done by focusing on prioritized customer needs, translating them into design requirements and then communicating them throughout the organization in a way to ensure that details can be quantified and controlled. The structure of HOQ would consist of six rooms and would transform the customer needs into product characteristics that would be further deployed to develop process and production plans [18]. A detailed of HOQ structure can be described as follows:

A detailed of House of Quality can be seen in Fig. 1.

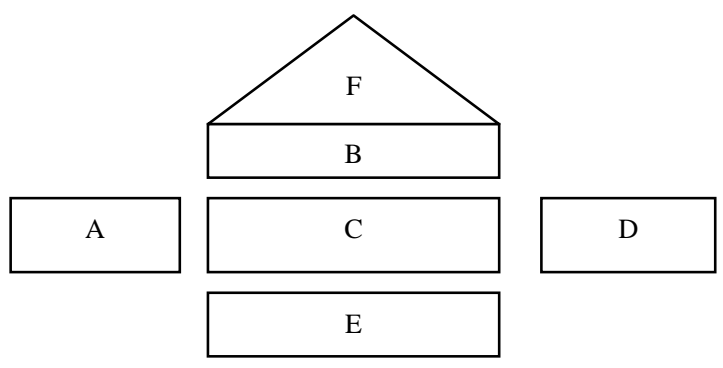

Fig. 1. House of quality.

A is customer requirements (Whats)

$\mathrm{B}$ is engineering characteristic (Hows)

$\mathrm{C}$ is the relationship between Whats and Hows

$\mathrm{D}$ is planning matrix

$\mathrm{E}$ is prioritizing characteristic engineering and target value

$\mathrm{F}$ is interrelationship between each engineering characteristic

\section{QUALITY FUNCTION DEPLOYMENT FOR ECO-FRIENDLY PRODUCT}

This paper proposes the integration of environmental requirements into QFD method for on the design of eco-friendly products. Environmental requirements have to be considered at the early stage of product design and development processes. The QFD method with the environmental consideration would help the team of product design at the manufacturing company identify the priorities of environmental indicators that have to be targeted as the improvement effort for creating eco-friendly product. The algorithm of the QFD with environmental concern can be described as follows:

\section{A. Identify Customer Requirements and Environmental Requirements}

The first step on the QFD method is how to identify voice of customer that would be called Whats on the HOQ. Due to the environmental consideration, the identification of the voice of customer not only based on the customer needs but also have to involve the environmental requirements. The environmental requirements for environmentally friendly product like energy consumption, less material use, reduce the waste and easy to disposal are possible to be considered during the production process. Masui et al [6] have proposed voice of customer (VOC) on environmental aspects through a whole life product cycle.

TABLE I: ENGINEERING REQUIREMENT (ADOPTED FROM MASUI ET AL [6])

Environmental requirements

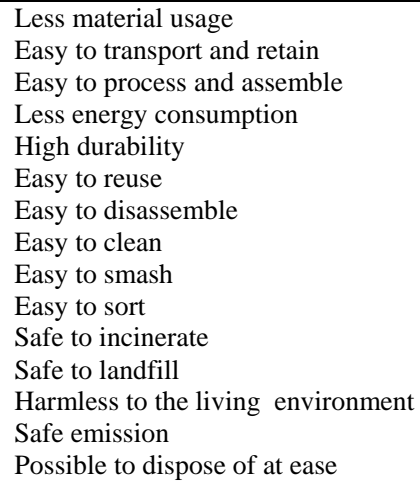

For the application at industry, these environmental requirements may be need to be rejected or need to be added by some other environmental requirements.

Historical data, brainstorming and deep discussion with some experts in the manufacturing industry could be employed in this stage to establish and translate these environmental requirements.

\section{B. Identify Technical Attributes}

The second step of the QFD approach is how to identify the technical attributes or technical characteristics, so called as Hows. The identification of technical attributes (Hows) is how to answer the customer environmental requirements (Whats). The process to identify technical attributes is wide, complex and uncertain. A systematic approach is needed to help the product development team identify technical 
attributes or technical characteristics. A life cycle analysis that would involve raw material, design and manufacture, distribution, use, and end life cycle is a recognized framework that can be used in this step to identify the significant technical attributes. A deep discussion and brainstorming that would involve cross function in the organization is necessary to be conducted. Masui et al [6] proposed engineering metrics (EM) on environmental aspects through a life cycle of product. For the implementation at industry, these engineering characteristic may be need to be added or rejected by some other engineering characteristics.

TABLE II: ENGINEERING METRIC (ADOPTED FROM MASUI ET AL, [6])

Environmental requirements

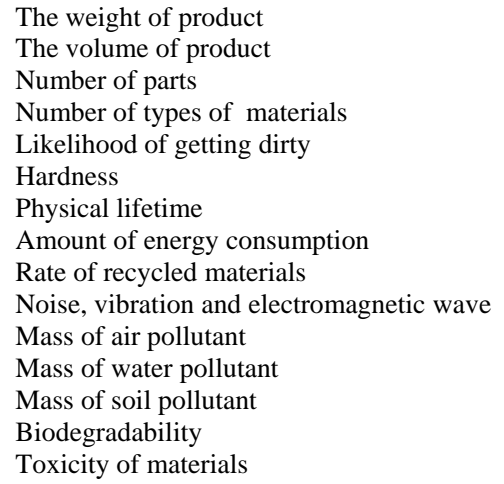

\section{Presentation of $Q F D$ with Environmental Concern}

After customer environmental requirements and technical attributes have been clearly identified, the next step is how to allocate weight to customer environmental requirements (Whats) and also how to identify the relationship matrix between Whats and technical attributes (Hows). This process would involve participation of some experts at manufacturing company that could be from cross function in the organisation like marketing, design and manufacturing. The main concern of QFD with environmental concern is how to construct the house of quality (HOQ) including weight allocation to customer environmental requirements and identify the relationship matrix between customer environmental requirements and technical attributes provided.

The illustrative relationship matrix is illustrated in Fig. 3. Where CER is customer and environmental requirements and TA is technical attributes.

$\begin{array}{cccccc} & T A_{1} & T A_{2} & T A_{3} & \cdots & T A_{m} \\ C E R_{1} & r_{11} & r_{12} & r_{13} & \cdots & r_{1 n} \\ C E R_{2} & r_{21} & r_{22} & r_{23} & \cdots & r_{2 n} \\ C E R_{3} & r_{31} & r_{32} & r_{33} & \cdots & r_{3 n} \\ \vdots & \vdots & \vdots & \vdots & & \vdots \\ C E R_{n} & r_{n 1} & r_{n 2} & r_{n 3} & \cdots & r_{n m}\end{array}$

Fig. 2. The relationship matrix of HOQ.

Commonly, the data for QFD method involves people assessment. The evaluation is by numerical rating to express people's feeling. The use of rating scale 1 to 9 is used where 1 means very unimportant and 9 means very important. The using of people's assessment would become subjective, vague and imprecise. The fuzzy logic approach that was developed to deal with the description activities, observations and judgments that are subjective, vague and imprecise would be employed to construct the HOQ including the identification of weight each customer environmental requirements and also the relationship matrix between whats and hows in the QFD method. Several experts from manufacturing company would be selected and they would give the assessment. The flow of fuzzy QFD can be described as follow:

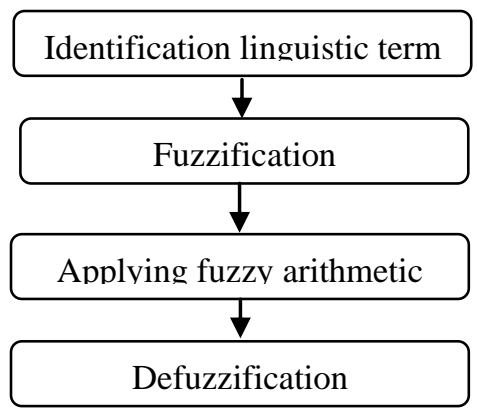

Fig. 3. The algorithm of fuzzy QFD.

Step 1: Identification linguistic term

The linguistic term is employed in this research and then transformed into triangular fuzzy number (TFN) to represent the assessment. To express the assessment the usage of linguistic term is more comfortable than numerical numbers. Several linguistic terms are used to express people's assessment. For example: very unimportant (VU), unimportant (U), medium (M), important (I), and very important (VI).

Step 2: Fuzzification

This step is concerned with the selection of the appropriate membership function of fuzzy sets. Many types of membership functions like triangular, trapezoidal, bell shaped and Gaussian curve can be used. This research presents the use of triangular fuzzy number that can be denoted as $\mathrm{M}=(\mathrm{a}, \mathrm{b}, \mathrm{c})$ where $\mathrm{a} \leq \mathrm{b} \leq \mathrm{c}$, a for lower value, $\mathrm{b}$ for mid value and $c$ for upper value. The qualitative assessment of each customer and environmental requirement would be evaluated and fuzzified to the triangular fuzzy number (TFN). An example of Triangular fuzzy number quantification is very unimportant $(1,1,2)$, unimportant $(2,3,4)$, Medium $(4,5,6)$, Important $(6,7,8)$ and very important $(8,9,9)$.

Step 3: Applying fuzzy arithmetic

Some experts at manufacturing industry would be selected for the assessment of QFD with environmental consideration. Fuzzy arithmetic operation like addition and scalar multiplication are used to calculate the weight of customer environmental requirements and also to identify the relationship matrix between customer environmental requirements and technical attributes in the house of quality.

\section{Step 4: Defuzzification}

Since the fuzzy result from fuzzy arithmetic operation is TFNs, these numbers need to be change into crisp value by defuzzification.

\section{Prioritize Objective Improvement Model for Improvement Effort}


The purpose of the QFD with environmental concern is to identify the most significant and important technical attributes provided. A technical attributes value can be calculated by multiplication between the weight of each customer and environmental requirements (CER) and the relationship matrix between CER and technical attributes.

The total value of each technical attributes can be formulated as $A$.

$$
A_{j}=\sum_{i=1}^{n} w_{i} r_{i j} \quad \text { for } j=1,2, \ldots, m
$$

where: $A_{j}$ is potential improvement for $\mathrm{TA}_{\mathrm{j}}$

$w_{i}$ is weight for $\mathrm{CER}_{\mathrm{i}}$

$r_{i j}$ is relationship between $\mathrm{CER}_{\mathrm{i}}$ and $\mathrm{TA}_{\mathrm{j}}$

$n$ is number of CER

$m$ is number of TA

\section{ILLUSTRATIVE EXAMPLE}

To implement the proposed methodology, the real case study at manufacturing is selected. Several experts from cross function of industry are involved (marketing, design, manufacturing, environmental). Based on the literature review, historical data, brainstorming and a deep discussion with some experts at the manufacturing company, then the team design identify 14 customer and environmental requirements (CER). They are: waste reduction, pollution impact reduction, less material usage, easy to transport, easy to process, less energy usage, easy to reuse, easy to smash, easy to sort, safe to incinerate, safe to landfill, harmless to the living environment, safe emission and possible to dispose of at ease.

Some experts would be selected to make the assessment for the QFD method. The calculation of weight of CER by using fuzzy approach. The linguistic term that would be trasformed into TFNs is used to represent the ranking of importance of each CER. For illustrative example, the weight of CER based on the fuzzy QFD can be seen in Table III.

TABLE III: THE WEIGHT OF CER BASED ON THE FUZZY QFD

\begin{tabular}{|c|c|c|c|c|c|}
\hline Environmental requirements & Expert 1 & Expert 2 & Expert 3 & Weight & Crisp value \\
\hline waste reduction & $(6,7,8)$ & $(6,7,8)$ & $(6,7,8)$ & $(6,7,8)$ & 7.25 \\
\hline pollution impact reduction & $(6,7,8)$ & $(8,9,9)$ & $(8,9,9)$ & $(7.33,8.33,8.67)$ & 8.25 \\
\hline less material usage & $(6,7,8)$ & $(6,7,8)$ & $(8,9,9)$ & $(6.67,7.67,8.33)$ & 7.75 \\
\hline easy to transport & $(6,7,8)$ & $(6,7,8)$ & $(4,5,6)$ & $(5.33,6.33,7.33)$ & 6.58 \\
\hline easy to process & $(6,7,8)$ & $(8,9,9)$ & $(8,9,9)$ & $(7.33,8.33,8.67)$ & 8.25 \\
\hline less energy usage & $(8,9,9)$ & $(8,9,9)$ & $(8,9,9)$ & $(8,9,9)$ & 8.75 \\
\hline easy to reuse & $(8,9,9)$ & $(6,7,8)$ & $(8,9,9)$ & $(7.33,8.33,8.67)$ & 8.25 \\
\hline easy to smash & $(4,5,6)$ & $(6,7,8)$ & $(6,7,8)$ & $(5.33,6.33,7.33)$ & 6.58 \\
\hline easy to sort & $(6,7,8)$ & $(4,5,6)$ & $(6,7,8)$ & $(5.33,6.33,7.33)$ & 6.58 \\
\hline safe to incinerate & $(4,5,6)$ & $(8,9,9)$ & $(8,9,9)$ & $(6.67,7.67,8)$ & 7.58 \\
\hline safe to landfill & $(6,7,8)$ & $(8,9,9)$ & $(8,9,9)$ & $(7.33,8.33,8.67)$ & 8.25 \\
\hline harmless to the living environment & $(8,9,9)$ & $(6,7,8)$ & $(8,9,9)$ & $(7.33,8.33,8.67)$ & 8.25 \\
\hline safe emission & $(4,5,6)$ & $(6,7,8)$ & $(6,7,8)$ & $(5.33,6.33,7.33)$ & 6.58 \\
\hline possible to dispose of at ease & $(4,5,6)$ & $(8,9,9)$ & $(8,9,9)$ & $(6.67,7.67,8)$ & 7.58 \\
\hline
\end{tabular}

Furthermore, life cycle analysis and deep discussion with some experts are conducted to deploy technical attributes. The relationship matrix between CER and technical attributes could be identified.

The calculation of this matrix also uses fuzzy approach.The most priority of the environmental indicators can be identified based on the highest value of technical attributes provided. These indicators can be put as a target improvement effort for the product development process.

\section{CONCLUSION}

QFD is an effective methodology for product design and development with the main aim to enhance customer satisfaction and has been conducted successfully in many industries. This paper proposes the integration of environmental requirements into QFD method for designing environmentally friendly product. Fuzzy logic is applied to deal with the description, subjective, imprecise and vague activities using membership functions to generate appropriate weights for each environmental requirement. These weights were used in conjunction with HOQ to determine the priority order of environmental indicators.

\section{ACKNOWLEDGMENT}

This work was supported in part by the Directorate of Higher Education Indonesia (DIKTI) and University of Muhammadiyah Gresik, East Java, Indonesia under Grant Beasiswa Luar Negeri (BLN) DIKTI.

\section{REFERENCES}

[1] P. Pusporini, K. Abhary, and L. Luong, "Introducing environmental aspects into lean six sigma concept for sustainable product development: A literature survey," in Proc. the 12th International Conference on QiR (Quality in Research), 4-7 July 2011. Bali, Indonesia.

[2] R. Karlsson and C. Luttropp, "EcoDesign: What's happening? An overview of the subject area of EcoDesign and of the papers in this 
special issue," Journal of Cleaner Production, vol. 14, no. 15-16, pp. 1291-1298, 2006.

[3] E. E. Karsak, "Fuzzy multiple objective programming framework to prioritize design requirements in quality function deployment," Computers and amp, Industrial Engineering, vol. 47, no. 2-3, pp $149-163,2004$

[4] A. Cristofari, M. Deshmukh, and B. Wang, "Green quality function deployment," in Proc. 4th International Conference on Environmentally Conscious Design and Manufacturing, 1996, Cleveland, Ohio.

[5] Y. Zhang, , H. P. Wang, and C. Zhang, "Green QFD-II: A life cycle approach for environmentally conscious manufacturing by integrating LCA and LCC into QFD matrices," International Journal of Production Research, vol. 37, no. 5, pp. 1075, 1999.

[6] K. Masui et al., "Applying quality function deployment to environmentally conscious design," International Journal of Quality and Reliability Management, vol. 20, no. 1, pp. 90-106, 2003.

[7] T. Sakao, "A QFD-centred design methodology for environmentally conscious product design," International Journal of Production Research, vol. 45, no. 18-19, pp. 4143-4162, 2007.

[8] E. Cagno and P. Trucco, "Integrated green and quality function deployment," International Journal Product Lifecycle Management, vol. 2 , no. 1 , pp. 64-83, 2007

[9] T. C. Kuo, H. H. Wu, and J. I. Shieh, "Integration of environmental considerations in quality function deployment by using fuzzy logic," Expert Systems with Applications, vol. 36, no. 3, part 2, pp. 7148-7156, 2009.

[10] M. D. Bovea and B. Wang, "Identifying environmental improvement options by combining life cycle assessment and fuzzy set theory," International Journal of Production Research, vol. 41, no. 3, pp. 593-609, 2003.

[11] P. Pusporini, K. Abhary, and L. Luong, "Environmental performance as key performance indicators in the lean six-sigma methodology," Advanced Materials Research, vol. 488-489, pp. 1082-1086, 2012.

[12] K. C. Tan, M. Xie, and E. Chia, "Quality function deployment and its use in designing information technology systems," International Journal of Quality and Reliability Management, vol. 15, no. 6, pp. 634-645, 1998

[13] A. R. A. Rahim and M. S. N. Baksh, "Application of quality function deployment (QFD) method for pultrusion machine design planning," Industrial Management and Data Systems, vol. 103, no. 6, pp. 373-387, 2003.

[14] A. Kumar, J. Antony, and T. S. Dhakar, "Integrating quality function deployment and benchmarking to achieve greater profitability," Benchmarking: An International Journal, vol. 13, no. 3, pp. 290-310, 2006.

[15] M. Celik et al., "An integrated fuzzy QFD model proposal on routing of shipping investment decisions in crude oil tanker market," Expert Systems with Applications, vol. 36, no. 3, part 2, pp. 6227-6235, 2009.

[16] G. Kannan, "Implementation of fuzzy quality function deployment in an automobile component to improve the quality characteristics," Quality Engineering, vol. 20, no. 3, pp. 321-333, 2008.

[17] E. E. Karsak, "Fuzzy multiple objective decision making approach to prioritize design requirements in quality function deployment," International Journal of Production Research, vol. 42, no. 18, pp. 3957-3974, 2004.
[18] L. K. Chan and M. L. Wu, "Quality function deployment: A comprehensive review of its concepts and methods," Quality Engineering, vol. 15, no. 1, pp. 23, 2002.

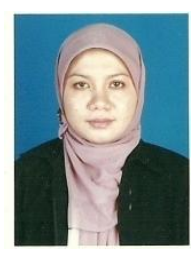

Pregiwati Pusporini is Ph.D. student at the School of Advanced Manufacturing and Mechanical Engineering, University of South Australia and Lecturer at Department of Industrial Engineering, University of Muhammadiyah Gresik, East Java, Indonesia. She got Indonesian government scholarship for doing her Ph.D. She graduated Bachelor of Engineering in Industrial Engineering from ITN, Malang, East Java, Indonesia and Master of Engineering in Industrial Engineering from ITS Surabaya, East Java, Indonesia. Her research interests in Quality, Six Sigma, Lean, Lean Six Sigma and QFD.

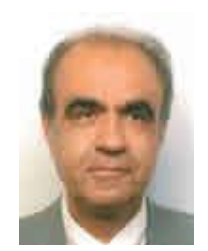

Kazem Abhary is a professor in sustainable mech. and manufacturing design, at School of Advanced Manufacturing and Mechanical Engineering, University of South Australia. He holds B. Engineering and M. Eng in Mechanical Engineering from Tehran University, M Eng (by research) and Ph.D. in Mechanical Engineering from University of Manchester, Institute of Science and Technology. He is a member of American Society of Mechanical Engineers (ASME), American Society for Engineering Education (ASEE), Australian Association for Engineering Education (AAEE), International Society for Computational Engineering and Sciences. He has an extensive list of publications including numerous international journal and conference papers, two handbook chapters, seven book chapters, four books and a bi-lingual Mechanical Engineering Lexicon, and also published a number of non technical articles on social and literary issues. He is on the editorial board of three International Engineering Journals. His research interests in Design for Manufacture, Assembly and Disassembly, Intelligent Design for Automation, Green (sustainable) Mechanical and Manufacturing Design, Design of Machinery and Vibrations, Computer Aided Design of Mechanical System, Mechanical Structures and Pipelines.

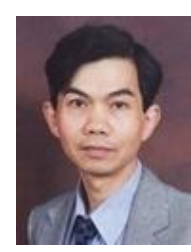

Lee Luong is professor of manufacturing engineering at the School of Advanced Manufacturing and Mechanical Engineering, University of South Australia. He graduated B. Eng. (Hons), Ph.D. from Monash. He has had extensive experience in teaching, research and academic development within the tertiary sector as well as with industry. Prior to joining the University of South Australia, he worked for more than ten years outside the academic environment, including the mining industry, commonwealth Scientific and Industrial Research Organisation (CSIRO), and Defence Science and Technology Organisation (DSTO). He has an extensive list of publications in international journals and conferences with ten book chapters, forty five journal articles and more than one hundred refereed papers in international conferences. He was The Asia Pacific Editor of the International Journal of Robotics and Computer Integrated Manufacturing for five years and currently on its Editorial Board. His research interests is in the areas of Logistics and Supply Chain Management (Distribution Network Design, Design for Recyclability and Product Upgrade, Close-loop Supply Chain, LCA and Environmental Impact Assessment), and Cellular and Flexible Manufacturing Systems. 